\title{
Interaction of streptococcal plasminogen binding proteins with the host fibrinolytic system
}

\author{
Marcus Fulde ${ }^{1}$, Michael Steinert ${ }^{2}$ and Simone Bergmann ${ }^{2 *}$ \\ 1 Institute for Medical Microbiology and Hospital Epidemiology, Hannover Medical School, Hannover, Germany \\ ${ }^{2}$ Department of Infection Biology, Institute of Microbiology, Technische Universität Braunschweig, Braunschweig, Germany
}

\section{Edited by:}

Paul De Figueiredo, Texas A\&M

University, USA

Reviewed by:

Qing-Ming Qin, Jilin University,

China

Neetu Singh, Texas A\&M University, USA

\section{*Correspondence:}

Simone Bergmann, Department of Infection Biology, Institute of

Microbiology, Technische

Universität Braunschweig,

Biocentre, Spielmannstr. 7,

38106 Braunschweig, Germany

e-mail: simone.bergmann@tu-bs.de
The ability to take advantage of plasminogen and its activated form plasmin is a common mechanism used by commensal as well as pathogenic bacteria in interaction with their respective host. Hence, a huge variety of plasminogen binding proteins and activation mechanisms exist. This review solely focuses on the genus Streptococcus and, in particular, on the so-called non-activating plasminogen binding proteins. Based on structural and functional differences, as well as on their mode of surface linkaging, three groups can be assigned: M-(like) proteins, surface displayed cytoplasmatic proteins with enzymatic activities ("moonlighting proteins") and other surface proteins. Here, the plasminogen binding sites and the interaction mechanisms are compared. Recent findings on the functional consequences of these interactions on tissue degradation and immune evasion are summarized.

Keywords: plasminogen, Streptococcus, enolase, M-protein, SCM, transmigration, phagocytosis

\section{INTRODUCTION}

In addition to a largely commensal lifestyle reflected by colonization of mucosal surfaces, species like S. pyogenes (group A streptococci, GAS) and S. pneumoniae appear as opportunistic pathogens causing a wide spectrum of local and systemic diseases in humans. In agriculture, subclinical infections with Streptococcus sp. lead to high financial deficits and an increasing demand for pets fosters the occurrence of streptococcal species in companion animals (Devriese et al., 1986; Staats et al., 1997; van der Linden et al., 2009). Interspecies jumps which might result in real zoonoses, therefore, represent a new attribute of streptococcal infections (Tang et al., 2006; Chen et al., 2007; Fittipaldi et al., 2012; Fulde and Valentin-Weigand, 2013).

Despite the large number of streptococcal species present in a broad variety of different hosts, pathogenesis and clinical signs appears highly similar. This implies that comparable virulence traits exist. The utilization of plasminogen for bacterial adherence to cell surfaces, dissemination in the body, and protection against immune defense represents a complex pathomechanism that reflects the sophisticated adaptation of streptococci to their host environments. Although genetically closely related, streptococci harbor a broad variety of different plasminogen bindingand activation mechanisms. Therefore, this genus represents a suitable model for discussing bacteria-plasminogen interactions.

Plasminogen is a $92 \mathrm{kDa}$ zymogen of the broad-spectrum serine protease plasmin. It is composed of an $8 \mathrm{kDa}$ pre-activation peptide, five homologous amino acid stretches forming a triple loop structure (Kringle domains, K1-5), and a C-terminal protease domain $(25 \mathrm{kDa})$. A functional attribute of the Kringle domains is their affinity to lysine (lysine-binding sites) in a very pronounced hierarchical order: $\mathrm{K} 1>\mathrm{K} 3>\mathrm{K} 4>\mathrm{K} 5$ except $\mathrm{K} 2$ which has negligible affinity to lysine (Miyashita et al., 1988; Marti et al., 1997). The protein comprising the first four Kringle domains (K1-4) shows inhibitory effect on angiogenesis and is, therefore, designated angiostatin. In contrast, the protein fragment containing the subdomain $\mathrm{K} 5$ and the serine protease domain is known as mini-plasminogen (mPLG). The detailed role of this fragment in physiology is still unknown.

In the fibrinolytic process, plasminogen is cleaved into the two-chained serine protease plasmin by two host-derived activators, the tissue-type plasminogen activator (tPA) and the urokinase-type plasminogen activator (uPA) (Dano et al., 1985). Plasmin-mediated cleavage of circulating native plasminogen (named Glu-plasminogen according to the first $\mathrm{N}$-terminal amino acid) results in a truncated form of the zymogen called Lys plasminogen $(\sim 83 \mathrm{kDa})$, which is more rapidly converted into plasmin. Streptococci activate plasminogen either via an endogenously produced streptokinase (Castellino and Violand, 1979) or by subversion of the host-derived activators, tPA, and uPA. Irrespective of expression of a bacterial plasminogen activator, the additional subversion of host-derived activators clearly demonstrates that bacteria have evolved efficient compensatory strategies to gain benefit from recruited plasmin activity.

This mini-review aims to provide a current overview about the fast-growing group of streptococcal proteins mediating plasminogen binding.

\section{STREPTOCOCCAL PLAMINOGEN BINDING PROTEINS}

The relevance of plasminogen binding in streptococcal pathogenesis is documented by an increasing amount of literature published in the last years (Bergmann et al., 2001, 2005; Sun et al., 2004; Sanderson-Smith et al., 2008; Fulde et al., 2011; Siemens et al., 2011; Teles et al., 2012; Agarwal et al., 2013). The structure of bacterial receptors, their surface linkage, and their mechanism of plasminogen binding differ significantly. Based on this, three groups of proteins can be assigned (Table 1): (a) 
Table 1 | Plasminogen-binding proteins of different streptococci and additional functions.

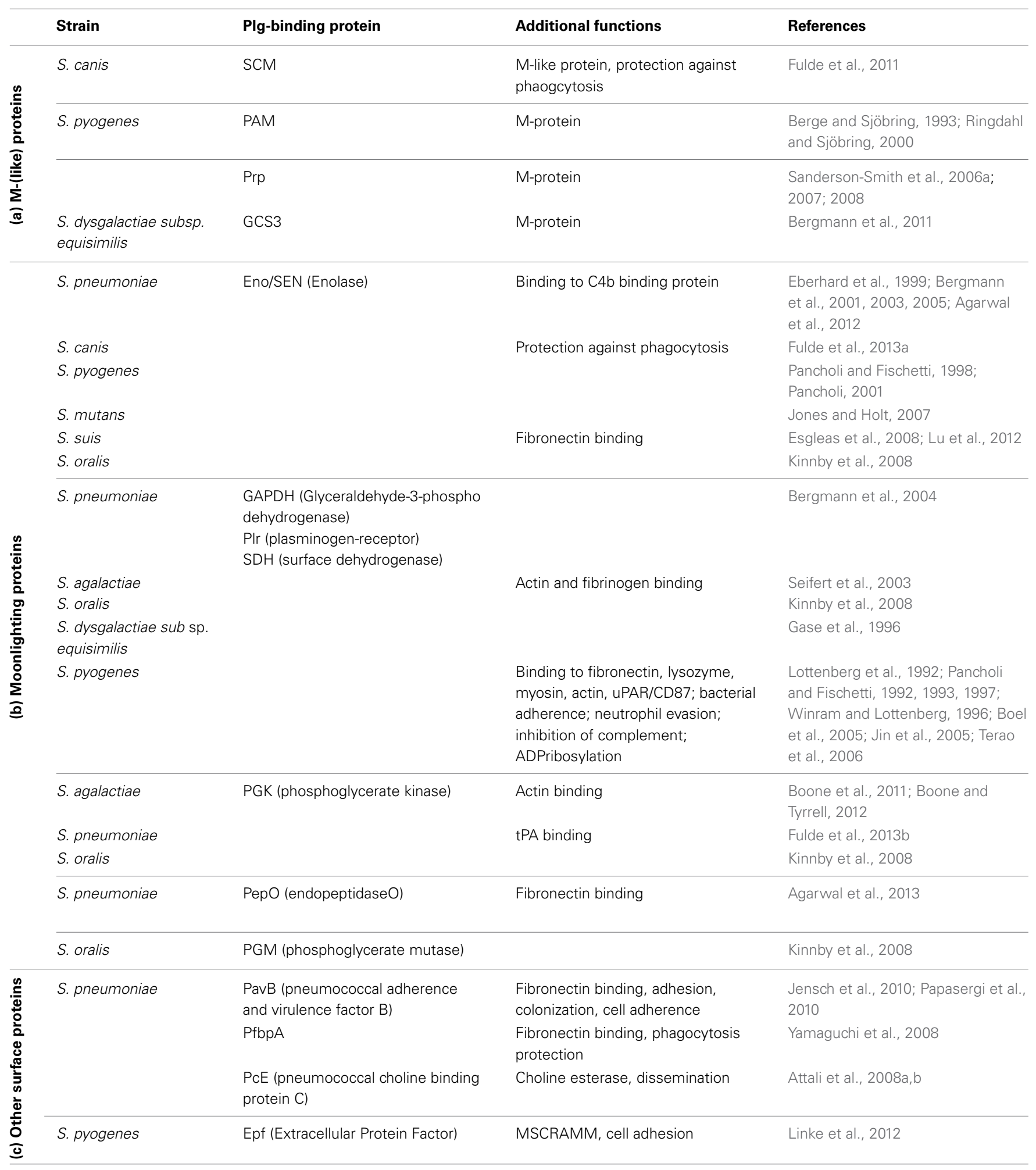

the M- and M-like proteins of pyogenic streptococci, e.g., $S$. canis, GAS, and S. dysgalactiae subs. equisimilis ( $S$. equisimilis) represent a first group (Berge and Sjöbring, 1993; SandersonSmith et al., 2006a,b; Bergmann et al., 2011; Fulde et al., 2011, 2013a). These proteins harbor a fibrillar structure with the tendency to dimerize and are covalently linked to the bacterial cell wall via a typical LPxTG motif (Fischetti, 1991). In 1995; Wistedt and co-workers identified $\mathrm{K} 2$ as the interaction site 
of the GASM Protein PAM (Table 1) (Wistedt et al., 1995). In contrast, SCM, a M-like protein of $S$. canis, and the $M$ protein GCS3 of $S$. equisimilis interact with mPLG (Table 1) (Bergmann et al., 2011; Fulde et al., 2011, 2013a). (b) The second group includes several enzymes of the glycolytic pathway like enolase, phosphoglycerate kinase (PGK), and glyceraldhehyde3-phosphate-dehydrogenase (GAPDH), a surface dehydrogenase $(\mathrm{SDH})$. These proteins are transported to the bacterial surface by a yet unknown mechanism and comprise moonlighting functions. In contrast to SCM and GCS3, the plasminogen binding site for streptococcal enolase and PGK was narrowed down to the angiostatin domain (Fulde et al., 2013a,b). It is supposed that this interaction leads to an opening of the plasminogen molecule conformation and to an enhanced plasmin generation (Miles and Plow, 1985; Plow et al., 1986). The expression of a subset of plasminogen binding proteins might also increase the amount of plasminogen molecules recruited to the bacterial surface and the generated plasmin activity. Such a cooperative interaction with plasminogen was recently described for the zoonotic pathogen S. canis: while the M protein SCM specifically interacts with mPLG, enolase binds to angiostatin leading to formation of a multi-protein complex on the bacterial surface (Figure 1) (Fulde et al., 2013a). (c) A third group of plasminogen binding proteins comprises covalently and noncovalently cell wall linked surface proteins, e.g., the pneumococcal adherence and virulence factor $\mathrm{B}$ (PavB) and the pneumococcal choline esterase (Pce) (Attali et al., 2008a,b; Jensch et al., 2010). These proteins share a stalk-domain containing repetitive amino acid sequences, which mediate plasminogen and fibronectin binding and attachment to phosphoryl moieties of the cell wall.

\section{PLASMINOGEN BINDING SITES}

For a long period of time, C-terminally located lysine residues of bacterial proteins were assumed to constitute the exclusive binding sites significantly participating in the interaction of plasminogen with host proteins like fibrin(ogen), alpha2antiplasmin, eukaryotic enolase, and cell-surface receptors (Miles et al., 1991; Ponting et al., 1992). Meanwhile, additional internal positively charged amino acid motifs had been identified as important binding sites for the pneumococcal enolase and pneumococcal endopeptidase O (PepO) (Table 1), as well as for the M-proteins of S. canis and GAS (Wistedt et al., 1995; Bergmann et al., 2003; Sanderson-Smith et al., 2006b, 2007, 2012; Fu et al., 2008; Fulde et al., 2011; Agarwal et al., 2013). The differences in the localization of plasminogen binding sites can be explained by the composition of the three dimensional protein structures referring to enolase as a typical example. In contrast to the dimeric eukaryotic enolase, streptococcal enolase is usually present in an octameric form (Ehinger et al., 2004; Lu et al., 2012). The complex globular structure of the octameric molecule hides C-terminal lysine residues in interdimer grooves, thereby maintaining structural integrity. Similarly, an internal binding site was recently discovered for the dimeric PGK of $S$. agalactiae and of $S$. pneumoniae, and also for the M-protein PAM of S. pyogenes (Boone and Tyrrell, 2012; Fulde et al., 2013b). The interaction of the M-like protein PAM with plasminogen is mediated by two N-terminally located repeat sequences designated a1 and a2. Interestingly, in contrast to what is known for other binding motifs, an arginine, and histidine, but not lysine represent the essential amino acids mediating protein-protein interaction (Walker et al., 2005; Sanderson-Smith et al., 2007). In conclusion, despite the variations in structure and amino acid composition of plasminogen binding motifs, the presence of positively charged amino acids in a hydrophobic surrounding seems to constitute the principal requirement for binding to plasminogen.

\section{PLASMINOGEN-MEDIATED INTERACTION}

Plasminogen circulates as a mono-chained multi-domain protein in the blood of vertebrates (Pollanen et al., 1991). Even without activation, recruitment of plasminogen to the bacterial surface has been reported as pivotal pathogenicity mechanism promoting bacterial attachment to cell surfaces (Lottenberg et al., 1994). Remarkably, intranasal mouse infection studies demonstrated that plasminogen recruitment to pneumococci significantly contribute to virulence in mice (Bergmann et al., 2003). Bacterial interaction with the host fibrinolytic system represents a double edged sword. While plasminogen binding to some commensals enhances bacterial colonization and protects tissues against access by pathogens, subversion of plasmin-mediated proteolysis by pathogens promotes infection with occasionally severe pathophysiological consequences. Several publications elucidate detailed mechanisms of plasmin activity recruited on streptococcal surface via single streptococcal plasminogen binding proteins (refer to references listed in Table 1).

\section{PLASMINOGEN BINDING PROTEINS PROMOTE ATTACHMENT TO PROTEINS OF THE EXTRACELLULAR MATRIX}

Interaction of streptococcal enolase with plasminogen has been reported for many species of the genus Streptococcus (Pancholi and Fischetti, 1992; Bergmann et al., 2001; Itzek et al., 2010; Fulde et al., 2013a). Its role in pathogenicity has been analyzed using a variety of in vivo and ex vivo infection models (Pancholi and Fischetti, 1998; Pancholi and Chhatwal, 2003; Bergmann et al., 2005, 2013; Agarwal et al., 2012). In addition, many moonlighting proteins have been characterized as adhesive molecules mediating streptococcal binding to proteins of the extracellular matrix (ECM) like fibronectin (Table 1) (Pancholi and Fischetti, 1992; Seifert et al., 2003; Bergmann and Hammerschmidt, 2006; Esgleas et al., 2008; Paterson and Orihuela, 2010; Bernardo-Garcia et al., 2011; Voss et al., 2012). This interaction promotes the contact of the bacteria with epithelial and endothelial cell surfaces (Esgleas et al., 2008) and contributes to bacterial colonization of host niches. Importantly, the cooperative binding activity of plasminogen and fibronectin is not only restricted to surface-displayed glycolytic enzymes but has also been demonstrated for non-glycolytic proteins, i.e., PavB, $\mathrm{PfbA} / \mathrm{B}$, and $\mathrm{PepO}$ of $S$. pneumoniae and Epf of GAS (Table 1) (Yamaguchi et al., 2008; Jensch et al., 2010; Papasergi et al., 2010; Linke et al., 2012; Agarwal et al., 2013). 


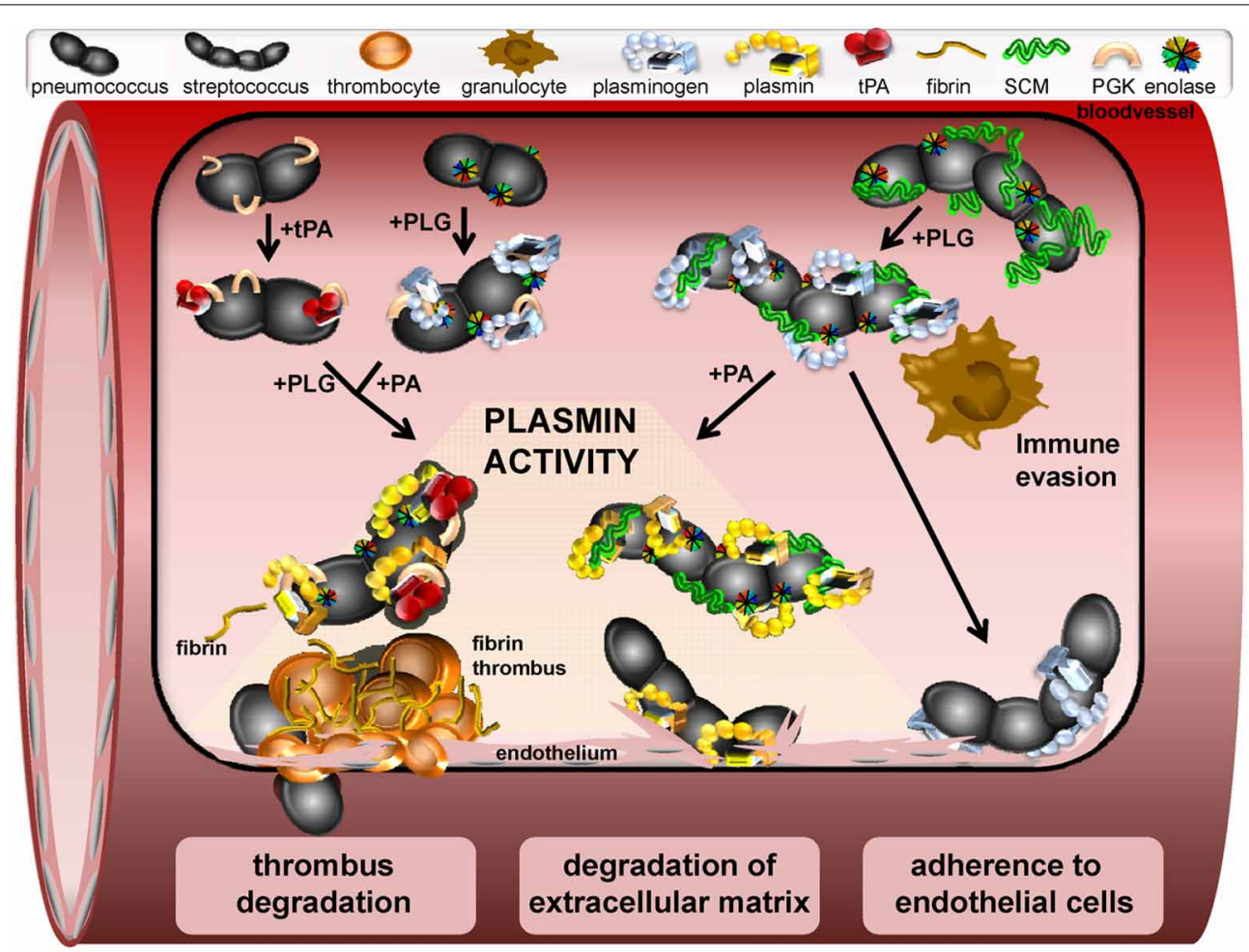

FIGURE 1 | Schematic model of a window section through a microvessel, presenting different functional mechanisms induced by interaction of streptococci with plasminogen and plasmin. In the upper left site, binding of tPA to the pneumococcal PGK and binding of PLG to surface displayed moonlighting proteins is shown.

Subsequent recruitment of PLG and a plasminogen activator leads to generation of plasmin activity on the bacterial surface. Similarly, PLG binding to streptococcal M-and M-like-proteins is followed by activation to plasmin via host-derived activators (upper right). Plasminogen binding also protects against phagocytic killing by granulocytes and macrophages and promotes adherence to endothelial cells (bottom right). Dissolution of fibrin thrombi by surface-bound plasmin-activity facilitating streptococcal transmigration is depicted on the lower left. Proteolytic degradation of extracellular matrix by recruited plasmin activity promotes bacterial-cell contact and pericellular transmigration as illustrated at the bottom center.

\section{ROLE OF PLASMINOGEN IN BACTERIAL-HOST CELL ADHESION AND INTERNALIZATION}

In addition to the support of bacterial colonization, binding of ECM-proteins to bacteria has been shown to promote activation of fibronectin-specific integrin receptors, which induces bacterial uptake (Hoffmann et al., 2010; Jensch et al., 2010). Similar to fibronectin, plasminogen mediates adherence of GAS to integrin receptors and triggers bacterial internalization into the cells (Siemens et al., 2011). Interestingly, recent data also demonstrates an adhesive effect of plasminogen when already bound to cell surfaces of epithelial and endothelial cells (Figure 1). As an example, surface-exposed enolase was identified as mediator for plasminogen-dependent bacterial attachment (Table 1) (Bergmann et al., 2013). In contrast to what has been shown for internalization of GAS, pneumococcal uptake in epithelial cells was not promoted by non-activated plasminogen. This strongly indicates an involvement of additional, yet unknown co-factors in cell entry mechanisms of GAS (Siemens et al., 2011).

Considering the conformation of plasminogen, two further interesting observations with respect to cell adhesion have been reported: while coating of pneumococci with Glu-plasminogen decreases attachment, pre-incubation of M-protein expressing
S. equisimilis with N-terminally truncated Lys-plasminogen resulted in enhanced bacterial adherence to nasopharyngeal cells (Bergmann et al., 2011). Since Lys-plasminogen possesses an open molecule form, the adhesive capacity may reflect a conformation dependent effect, as already mentioned in the literature (Marshall et al., 1994; Lahteenmaki et al., 2005).

\section{PLASMIN-MEDIATED INTERACTION}

Streptococci differ not only in their repertoire of plasminogen binding proteins but also in their intrinsic ability to activate the zymogen. While GAS and S. equisimilis express streptokinases, $S$. canis, $S$. pneumoniae, and most of the oral streptococci require host-derived uPA or tPA to convert plasminogen in its active form plasmin (Bergmann et al., 2005; Bergmann and Hammerschmidt, 2007; Kinnby et al., 2008; Itzek et al., 2010; Fulde et al., 2011). Although direct binding of plasminogen activators to streptococcal surface is not required for plasmin activation, a recent publication demonstrates a direct binding of tPA to the pneumococcal moonlighting protein PGK, which has been shown to promote plasminogen activation (Fulde et al., 2013b). In contrast to the cleavage mechanism by uPA and tPA, streptokinases form a protein complex which activates the enzyme domain 
of plasminogen (Boxrud and Bock, 2000; Boxrud et al., 2004). Moreover, immobilization of plasmin in fibrin fibers or on surfaces of cells protects the enzyme against inhibition by its major inhibitor the serpin $\alpha 2$ antiplasmin and also against inactivation via several streptokinase variants (Plow et al., 1986; Hall et al., 1991; Cook et al., 2012). The capture of plasminogen to the bacterial surface via non-activating plasminogen binding proteins induces conformational changes, which promote generation of plasmin activity by host-activators, although no protective effect against $\alpha 2$ antiplasmin inhibition is gained (Miles and Plow, 1985; Plow et al., 1986). Nevertheless, conversion of plasminogen to plasmin equips the bacteria with efficient proteolytic activity, which is targeted against plasmin substrates of the host.

\section{DEGRADATION OF FIBRIN THROMBI AND COMPONENTS OF THE EXTRACELLULAR MATRIX}

Severe systemic streptococcal infections are frequently accompanied by enhanced vascular coagulation, which entraps bacteria in fibrinous thrombi (Abraham, 2000; Gunther et al., 2000). Hence, utilization of proteolytic activity has been shown to promote bacterial escape from these entrapments and enable transmigration through ECM and vascular barriers (Lahteenmaki et al., 2001). In this regard, incubation of semi-synthetic fibrin thrombi with plasmin-coated pneumococci or $S$. canis resulted in a complete dissolution of the fibrin bundles (Figure 1) (Bergmann et al., 2005; Fulde et al., 2011). Even in the absence of a streptokinase, plasminogen recruitment is accomplished via a subset of surface displayed plasminogen binding proteins acting in a compensatory manner. Fibrinogen serves as a major target for plasmin proteolysis and has been identified as an important cofactor in streptokinase-dependent plasmin activation. The reported fibrinogen binding of group $\mathrm{A}$ and $\mathrm{B}$ streptococci has also been shown to improve the efficiency of fibrin clot degradation by plasmin independent of streptokinase activity (Seifert et al., 2003; Olsen et al., 2009).

In addition to fibrin degradation, recruitment of plasmin results in enhanced degradation of ECM glycoproteins like fibronectin and laminin, which weakens the matrix integrity and might provide a benefit for dissemination of non-motile streptococci (Figure 1) (Liotta et al., 1981; Bergmann et al., 2005; Attali et al., 2008a; Fulde et al., 2013a). Moreover, plasmin-mediated cleavage of cellular junction proteins is supposed to promote subsequent pericellular transmigration of bacteria, as has been proposed for group A streptococci by Pancholi and colleagues and for pneumococci by Attali and colleagues (Pancholi et al., 2003; Attali et al., 2008b). The entirety of reported functional effects of recruited plasmin activity elucidates the mechanisms of plasminogen recruitment as a key strategy of streptococci to facilitate their transmigration through tissue barriers thereby establishing an infection.

\section{THE ROLE OF PLASMINOGEN AND PLASMIN IN STREPTOCOCCAL IMMUNE EVASION}

Recruitment of host proteins to the streptococcal surface has been described as an efficient mechanism to circumvent innate immune strategies (Valenti-Weigand et al., 1996; Courtney et al.,
2006; Yamaguchi et al., 2008). Recent reports also demonstrate the protective function of streptococcal plasminogen thereby neutralizing the host immune defense. For example, plasminogenbinding to GAS markedly reduced phagocytic killing by macrophages (Figure 1, Siemens et al., 2011). Furthermore, disruption of plasminogen binding capacity significantly reduced virulence of GAS in a murine model of invasive streptococcosis (Sanderson-Smith et al., 2008). Here, the mortality of transgenic mice expressing human plasminogen was markedly increased after infection with GAS (Sun et al., 2004; Sanderson-Smith et al., 2008). This was attributed to streptokinase expression and confirmed the high impact of plasmin generation for severe infections in humans (Sun et al., 2004). Moreover, inactivation of genes encoding either PAM or streptokinase attenuated the pathogenic potential of many GAS strains isolated from skin infections (Kalia and Bessen, 2004). A similar phenotype was recently reported for the zoonotic pathogen $S$. canis: the cooperative binding of SCM and surface-exposed enolase to plasminogen leads synergistically to an increase in the anti-phagocytic capacity as compared to the plasminogen binding activity of each of them (Figure 1) (Fulde et al., 2013a).

Plasminogen binding proteins also shield bacteria from the attack of the complement system. The GAPDH of GAS binds and inhibits the chemotactic function of the complement factor C5a (Boel et al., 2005; Terao et al., 2006). Immune-modulating activities have also been reported for the pneumococcal plasminogen binding proteins enolase and PepO. Recruitment of C4b-binding protein to the pneumococcal surface via enolase leads to a decrease in $\mathrm{C} 3 \mathrm{~b}$ deposition and represents an effective mechanism of human complement control (Agarwal et al., 2012). Furthermore, immobilization of proteolytic plasmin activity on the pneumococcal surface via PepO leads to C3b cleavage and weakens the complement-based immune defense (Agarwal et al., 2013). Another protection mechanism is directed against the activity of antimicrobial peptides such as the cathelicidin LL-37, which is cleaved by streptococcal surface-bound plasmin (Figure 1) (Hollands et al., 2012). Thus, streptococcal interaction with the plasminogen system provides powerful protective strategies against various branches of immune defense.

\section{CONCLUDING REMARKS}

The increasing amount of publications on bacterial-plasminogen interaction reflects the high relevance of this topic in infection biology. The genus Streptococcus comprises around 60 species exhibiting commensal as well as pathogenic properties. Especially the pathogenic species like GAS, S. pneumoniae, S. canis, and S. suis, benefit from plasminogen recruitment in the infection process. Pyogenic streptococci like GAS, S. equisimilis, and $S$. canis use $\mathrm{M}$ and $\mathrm{M}$-like proteins to interact with plasminogen/plasmin. Since M proteins constitute the primary, covalently linked proteinous structure on the surface of many streptococci, this interaction is usually strong and correlates with the pathogenic potential of the respective isolate. Furthermore, GAS and $S$. equisimilis express plasminogen activators, which convert the surface-bound zymogen to its active, proteolytic form plasmin. In contrast, streptococci lacking M-proteins and streptokinases like S. pneumoniae and S. suis primarily use a subset 
of surface exposed proteins partially with moonlighting functions as plasminogen receptors. These proteins associate with the bacterial surface by a yet unknown mechanism and also the mode of anchorage remains still elusive. Therefore, the interaction between these proteins and plasminogen has long been regarded as non-essential and less relevant. Nowadays, complex formation between surface-exposed glycolytic enzymes and plasminogen/plasmin constitutes a well established explanation for systemic spread of bacteria lacking $M$ proteins or intrinsic activators such as streptokinases. A fundamental prerequisite in this context is the utilization or direct binding of host-derived plasminogen activators by plasminogen-coated bacteria to convert the surface bound zymogen into plasmin. Finally, the cooperative plasminogen binding of S. canis M-Protein and the moonlighting protein enolase nicely illustrates the sophisticated and efficient strategies of bacterial interaction with the fibrinolytic system of the host. Facing the problem of antibiotic resistances, a therapeutical inhibition of the interplay between streptococci and plasminogen might constitute an alternative approach to significantly reduce bacterial cell adherence, immune evasion, and tissue degradation and would provide a promising strategy for combating severe streptococcal infections.

\section{REFERENCES}

Abraham, E. (2000). Coagulation abnormalities in acute lung injury and sepsis. Am. J. Respir. Cell Mol. Biol. 22, 401-404. doi: 10.1165/ajrcmb.22.4.f184

Agarwal, V., Hammerschmidt, S., Malm, S., Bergmann, S., Riesbeck, K., and Blom, A. M. (2012). Enolase of Streptococcus pneumoniae binds human complement inhibitor C4b-binding protein and contributes to complement evasion. J. Immunol. 189, 3575-3584. doi: 10.4049/jimmunol.1102934

Agarwal, V., Kuchipudi, A., Fulde, M., Riesbeck, K., Bergmann, S., and Blom, A. M. (2013). Streptococcus pneumoniae Endopeptidase, O (PepO) Is a Multifunctional Plasminogen- and fibronectin-binding protein, facilitating evasion of innate immunity and invasion of host cells. J. Biol. Chem. 288, 6849-6863. doi: 10.1074/jbc.M112.405530

Attali, C., Frolet, C., Durmort, C., Offant, J., Vernet, T., and Di Guilmi, A. M. (2008a). Streptococcus pneumoniae choline-binding protein E interaction with plasminogen/plasmin stimulates migration across the extracellular matrix. Infect. Immun. 76, 466-476. doi: 10.1128/IAI.01261-07

Attali, C., Durmort, C., Vernet, T., and Di Guilmi, A. M. (2008b). The interaction of Streptococcus pneumoniae with plasmin mediates transmigration across endothelial and epithelial monolayers by intercellular junction cleavage. Infect. Immun. 76, 5350-5356. doi: 10.1128/IAI.00184-08

Berge, A., Sjöbring, U. (1993). PAM, a novel plasminogen-binding protein from Streptococcus pyogenes. J. Biol. Chem. 268, 25417-25424.

Bergmann, R., Dinkla, K., Nitsche-Schmitz, D. P., Graham, R. M., Luttge, M., Sanderson-Smith, M. L., et al. (2011). Biological functions of GCS3, a novel plasminogen-binding protein of Streptococcus dysgalactiae ssp. equisimilis. Int. J. Med. Microbiol. 301, 157-164. doi: 10.1016/j.ijmm.2010.06.007

Bergmann, S., and Hammerschmidt, S. (2006). Versatility of pneumococcal surface proteins. Microbiology 152, 295-303. doi: 10.1099/mic.0.28610-0

Bergmann, S., and Hammerschmidt, S. (2007). Fibrinolysis and host response in bacterial infections. Thromb. Haemost. 98, 512-520. doi: 10.1160/TH07-020117

Bergmann, S., Rohde, M., Chhatwal, G. S., and Hammerschmidt, S. (2001). alpha-Enolase of Streptococcus pneumoniae is a plasmin(ogen)-binding protein displayed on the bacterial cell surface. Mol. Microbiol. 40, 1273-1287. doi: 10.1046/j.1365-2958.2001.02448.x

Bergmann, S., Rohde, M., and Hammerschmidt, S. (2004). Glyceraldehyde-3phosphate dehydrogenase of Streptococcus pneumoniae is a surface-displayed plasminogen-binding protein. Infect. Immun. 72, 2416-2419. doi: 10.1128/IAI. 72.4.2416-2419.2004

Bergmann, S., Rohde, M., Preissner, K. T., and Hammerschmidt, S. (2005). The nine residue plasminogen-binding motif of the pneumococcal enolase is the major cofactor of plasmin-mediated degradation of extracellular matrix, dissolution of fibrin and transmigration. Thromb. Haemost. 94, 304-311. doi: 10.1160/TH05-05-0369

Bergmann, S., Schoenen, H., and Hammerschmidt, S. (2013). The interaction between bacterial enolase and plasminogen promotes adherence of Streptococcus pneumoniae to epithelial and endothelial cells. Int. J. Med. Microbiol. doi: 10.1016/j.ijmm.2013.06.002. [Epub ahead of print].

Bergmann, S., Wild, D., Diekmann, O., Frank, R., Bracht, D., Chhatwal, G. S., et al. (2003). Identification of a novel plasmin(ogen)-binding motif in surface displayed alpha-enolase of Streptococcus pneumoniae. Mol. Microbiol. 49, 411-423. doi: 10.1046/j.1365-2958.2003.03557.x

Bernardo-Garcia, N., Bartual, S. G., Fulde, M., Bergmann, S., and Hermoso, J. A. (2011). Crystallization and preliminary X-ray diffraction analysis of phosphoglycerate kinase from Streptococcus pneumoniae. Acta Crystallogr. Sect. F Struct. Biol. Cryst. Commun. 67, 1285-1289. doi: 10.1107/S1744309111030922

Boel, G., Jin, H., and Pancholi, V. (2005). Inhibition of cell surface export of group A streptococcal anchorless surface dehydrogenase affects bacterial adherence and antiphagocytic properties. Infect. Immun. 73, 6237-6248. doi: 10.1128/IAI.73.10.6237-6248.2005

Boone, T. J., Burnham, C. A., and Tyrrell, G. J. (2011).Binding of group B streptococcal phosphoglycerate kinase to plasminogen and actin. Microb. Pathog. 51, 255-261. doi: 10.1016/j.micpath.2011.06.005

Boone, T. J., and Tyrrell, G. J. (2012).Identification of the actin and plasminogen binding regions of group B streptococcal phosphoglycerate kinase. J. Biol. Chem. 287, 29035-29044. doi: 10.1074/jbc.M112.361261

Boxrud, P. D., and Bock, P. E. (2000). Streptokinase binds preferentially to the extended conformation of plasminogen through lysine binding site and catalytic domain interactions. Biochemistry 39, 13974-13981. doi: 10.1021/bi000594i

Boxrud, P. D., Verhamme, I. M., and Bock, P. E. (2004). Resolution of conformational activation in the kinetic mechanism of plasminogen activation by streptokinase. J. Biol. Chem. 279, 36633-36641. doi: 10.1074/jbc.M405264200

Castellino, F. J., and Violand, B. N. (1979). The fibrinolytic system-basic considerations. Prog. Cardiovasc. Dis. 21, 241-254. doi: 10.1016/0033-0620(79)90012-4

Chen, C., Tang, J., Dong, W., Wang, C., Feng, Y., Wang, J., et al. (2007). A glimpse of streptococcal toxic shock syndrome from comparative genomics of S. suis 2 Chinese isolates. PLoS ONE 2:e315. doi: 10.1371/journal.pone.0000315

Cook, S. M., Skora, A., Gillen, C. M., Walker, M. J., and McArthur, J. D. (2012). Streptokinase variants from Streptococcus pyogenes isolates display altered plasminogen activation characteristics - implications for pathogenesis. Mol. Microbiol. 86, 1052-1062. doi: 10.1111/mmi.12037

Courtney, H. S., Hasty, D. L., and Dale, J. B. (2006). Anti-phagocytic mechanisms of Streptococcus pyogenes: binding of fibrinogen to M-related protein. Mol. Microbiol. 59, 936-947. doi: 10.1111/j.1365-2958.2005.04977.x

Dano, K., Andreasen, P. A., Grondahl-Hansen, J., Kristensen, P., Nielsen, L. S., and Skriver, L. (1985). Plasminogen activators, tissue degradation, and cancer. $A d v$. Cancer Res. 44, 139-266. doi: 10.1016/S0065-230X(08)60028-7

Devriese, L. A., Hommez, J., Klipper-Bälz, R., and Schleifer, K.-H. (1986). Streptococcus canis sp. nov.: a species of Group G streptococci from animals. Int. J. Syst. Bacteriol. 36, 422-425. doi: 10.1099/00207713-36-3-422

Eberhard, T., Kronvall, G., and Ullberg, M. (1999). Surface bound plasmin promotes migration of Streptococcus pneumoniae through reconstituted basement membranes. Microb. Pathog. 26, 175-181. doi: 10.1006/mpat.1998.0262

Ehinger, S., Schubert, W. D., Bergmann, S., Hammerschmidt, S., and Heinz, D. W. (2004). Plasmin(ogen)-binding alpha-enolase from Streptococcus pneumoniae: crystal structure and evaluation of plasmin(ogen)-binding sites. J. Mol. Biol. 343, 997-1005. doi: 10.1016/j.jmb.2004.08.088

Esgleas, M., Li, Y., Hancock, M. A., Harel, J., Dubreuil, J. D., and Gottschalk, M. (2008). Isolation and characterization of alpha-enolase, a novel fibronectinbinding protein from Streptococcus suis. Microbiology 154, 2668-2679. doi: 10.1099/mic. $0.2008 / 017145-0$

Fischetti, V. A. (1991). Streptococcal M protein. Sci. Am. 264, 58-65. doi: 10.1038/scientificamerican0691-58

Fittipaldi, N., Segura, M., Grenier, D., and Gottschalk, M. (2012). Virulence factors involved in the pathogenesis of the infection caused by the swine pathogen and zoonotic agent Streptococcus suis. Future Microbiol. 7, 259-279. doi: $10.2217 / \mathrm{fmb} .11 .149$

Fu, Q., Figuera-Losada, M., Ploplis, V. A., Cnudde, S., Geiger, J. H., Prorok, M., et al. (2008). The lack of binding of VEK-30, an internal peptide from the group A streptococcal M-like protein, PAM, to murine plasminogen is due to two 
amino acid replacements in the plasminogen kringle-2 domain. J. Biol. Chem. 283, 1580-1587. doi: 10.1074/jbc.M705063200

Fulde, M., Rohde, M., Hitzmann, A., Preissner, K. T., Nitsche-Schmitz, D. P., Nerlich, A., et al. (2011). SCM, a novel M-like protein from Streptococcus canis, binds (mini)-plasminogen with high affinity and facilitates bacterial transmigration. Biochem. J. 434, 523-535. doi: 10.1042/BJ20101121

Fulde, M., Rohde, M., Polok, A., Preissner, K. T., Chhatwal, G. S., and Bergmann, S. (2013a). Cooperative plasminogen recruitment to the surface of Streptococcus canis via M protein and enolase enhances bacterial survival. mBio 4, e00629-e00612. doi: 10.1128/mBio.00629-12

Fulde, M., Bernardo-García, N., Rohde, M., Nachtigall, N., Frank, R., Preissner, K. T., et al. (2013b). Pneumococcal phosphoglycerate kinase interacts with plasminogen and its tissue activator. Thromb. Haemost. 111. doi: 10.1160/TH1305-0421. [Epub ahead of print].

Fulde, M., and Valentin-Weigand, P. (2013).Epidemiology and pathogenicity of zoonotic streptococci. Curr. Top. Microbiol. Immunol. 368, 49-81. doi: 10.1007/82_2012_277

Gase, K., Gase, A., Schirmer, H., and Malke, H. (1996). Cloning, sequencing and functional overexpression of the Streptococcus equisimilis H46A gapC gene encoding a glyceraldehyde-3-phosphate dehydrogenase that also functions as a plasmin(ogen)-binding protein. Purification and biochemical characterization of the protein. Eur. J. Biochem. 239, 42-51. doi: 10.1111/j.14321033.1996.0042u.x

Gunther, A., Mosavi, P., Heinemann, S., Ruppert, C., Muth, H., Markart, P., et al. (2000). Alveolar fibrin formation caused by enhanced procoagulant and depressed fibrinolytic capacities in severe pneumonia. Comparison with the acute respiratory distress syndrome. Am. J. Respir. Crit. Care Med. 161, 454-462. doi: $10.1164 /$ ajrccm.161.2.9712038

Hall, S. W., Humphries, J. E., and Gonias, S. L. (1991).Inhibition of cell surface receptor-bound plasmin by alpha 2-antiplasmin and alpha 2-macroglobulin. J. Biol. Chem. 266, 12329-12336.

Hoffmann, C., Berking, A., Agerer, F., Buntru, A., Neske, F., Chhatwal, G. S., et al. (2010). Caveolin limits membrane microdomain mobility and integrin-mediated uptake of fibronectin-binding pathogens. J. Cell. Sci. 15 123, 4280-4291. doi: 10.1242/jcs.064006

Hollands, A., Gonzalez, D., Leire, E., Donald, C., Gallo, R. L., Sanderson-Smith, M., et al. (2012). A bacterial pathogen co-opts host plasmin to resist killing by cathelicidin antimicrobial peptides. J. Biol. Chem. 287, 40891-40897. doi: 10.1074/jbc.M112.404582

Itzek, A., Gillen, C. M., Fulde, M., Friedrichs, C., Rodloff, A. C., Chhatwal, G. S., et al. (2010). Contribution of plasminogen activation towards the pathogenic potential of oral streptococci. PLoS ONE 5:e13826. doi: 10.1371/journal.pone. 0013826

Jensch, I., Gamez, G., Rothe, M., Ebert, S., Fulde, M., Somplatzki, D., et al. (2010). PavB is a surface-exposed adhesin of Streptococcus pneumoniae contributing to nasopharyngeal colonization and airways infections. Mol. Microbiol. 77, 22-43. doi: 10.1111/j.1365-2958.2010.07189.x

Jin, H., Song, Y. P., Boel, G., Kochar, J., and Pancholi, V. (2005). Group A streptococcal surface GAPDH, SDH, recognizes uPAR/CD87 as its receptor on the human pharyngeal cell and mediates bacterial adherence to host cells. J. Mol. Biol. 350, 27-41. doi: 10.1016/j.jmb.2005.04.063

Jones, M. N., and Holt, R. G. (2007). Cloning and characterization of an alpha-enolase of the oral pathogen Streptococcus mutans that binds human plasminogen. Biochem. Biophys. Res. Commun. 364, 924-929. doi: 10.1016/j.bbrc.2007.10.098

Kalia, A., and Bessen, D. E. (2004). Natural selection and evolution of streptococcal virulence genes involved in tissue-specific adaptations. J. Bacteriol. 186, 110-121. doi: 10.1128/JB.186.1.110-121.2004

Kinnby, B., Booth, N. A., and Svensater, G. (2008).Plasminogen binding by oral streptococci from dental plaque and inflammatory lesions. Microbiology 154, 924-931. doi: 10.1099/mic.0.2007/013235-0

Lahteenmaki, K., Edelman, S., and Korhonen, T. K. (2005). Bacterial metastasis: the host plasminogen system in bacterial invasion. Trends Microbiol. 13, 79-85. doi: 10.1016/j.tim.2004.12.003

Lahteenmaki, K., Kuusela, P., and Korhonen, T. K. (2001). Bacterial plasminogen activators and receptors. FEMS Microbiol. Rev. 25, 531-552. doi: 10.1016/S01686445(01)00067-5

Linke, C., Siemens, N., Oehmcke, S., Radjainia, M., Law, R. H., Whisstock, J. C., et al. (2012). The extracellular protein factor Epf from Streptococcus pyogenes is a cell surface adhesin that binds to cells through an N-terminal domain containing a carbohydrate-binding module. J. Biol. Chem. 287, 38178-38189. doi: 10.1074/jbc.M112.376434

Liotta, L. A., Goldfarb, R. H., Brundage, R., Siegal, G. P., Terranova, V., and Garbisa, S. (1981). Effect of plasminogen activator (urokinase), plasmin, and thrombin on glycoprotein and collagenous components of basement membrane. Cancer Res. 41, 4629-4636.

Lottenberg, R., Broder, C. C., Boyle, M. D., Kain, S. J., Schroeder, B. L., and Curtiss, R. 3rd. (1992). Cloning, sequence analysis, and expression in Escherichia coli of a streptococcal plasmin receptor. J. Bacteriol. 174, 5204-5210.

Lottenberg, R., Minning-Wenz, D., and Boyle, M. D. (1994). Capturing host plas$\min (\mathrm{ogen})$ : a common mechanism for invasive pathogens. Trends Microbiol. 2, 20-24. doi: 10.1016/0966-842X(94)90340-9

Lu, Q., Lu, H., Qi, J., Lu, G., and Gao, G. F. (2012). An octamer of enolase from Streptococcus suis. Protein Cell 3, 769-780. doi: 10.1007/s13238-012-2040-7

Marshall, J. M., Brown, A. J., and Ponting, C. P. (1994). Conformational studies of human plasminogen and plasminogen fragments: evidence for a novel third conformation of plasminogen. Biochemistry 33, 3599-3606. doi: 10.1021/bi00178a017

Marti, D. N., Hu, C. K., An, S. S., von Haller, P., Schaller, J., and Llinas, M. (1997). Ligand preferences of kringle 2 and homologous domains of human plasminogen: canvassing weak, intermediate, and high-affinity binding sites by $1 \mathrm{H}-\mathrm{NMR}$. Biochemistry 36, 11591-11604. doi: 10.1021/bi971316v

Miles, L. A., Dahlberg, C. M., Plescia, J., Felez, J., Kato, K., and Plow, E. F. (1991). Role of cell-surface lysines in plasminogen binding to cells: identification of alpha-enolase as a candidate plasminogen receptor. Biochemistry 30, 1682-1691. doi: 10.1021/bi00220a034

Miles, L. A., and Plow, E. F. (1985). Binding and activation of plasminogen on the platelet surface. J. Biol. Chem. 260, 4303-4311.

Miyashita, C., Wenzel, E., and Heiden, M. (1988). Plasminogen: a brief introduction into its biochemistry and function. Haemostasis 18(Suppl. 1), 7-13.

Olsen, R. J., Shelburne, S. A., and Musser, J. M. (2009). Molecular mechanisms underlying group A streptococcal pathogenesis. Cell. Microbiol. 11, 1-12. doi: $10.1111 / j .1462-5822.2008 .01225 . x$

Pancholi, V. (2001). Multifunctional alpha-enolase: its role in diseases. Cell. Mol. Life Sci. 58, 902-920. doi: 10.1007/PL00000910

Pancholi, V., and Chhatwal, G. S. (2003). Housekeeping enzymes as virulence factors for pathogens. Int. J. Med. Microbiol. 293, 391-401. doi: 10.1078/14384221-00283

Pancholi, V., and Fischetti, V. A. (1992). A major surface protein on group A streptococci is a glyceraldehyde-3-phosphate-dehydrogenase with multiple binding activity. J. Exp. Med. 176, 415-426. doi: 10.1084/jem.176.2.415

Pancholi, V., and Fischetti, V. A. (1993). Glyceraldehyde-3-phosphate dehydrogenase on the surface of group A streptococci is also an ADP-ribosylating enzyme. Proc. Natl. Acad. Sci. U.S.A. 90, 8154-8158. doi: 10.1073/pnas.90. 17.8154

Pancholi, V., and Fischetti, V. A. (1997). A novel plasminogen/plasmin binding protein on the surface of group A streptococci. Adv. Exp. Med. Biol. 418, 597-599. doi: 10.1007/978-1-4899-1825-3_138

Pancholi, V., and Fischetti, V. A. (1998). alpha-enolase, a novel strong plas$\min ($ ogen) binding protein on the surface of pathogenic streptococci. J. Biol. Chem. 273, 14503-14515. doi: 10.1074/jbc.273.23.14503

Pancholi, V., Fontan, P., and Jin, H. (2003). Plasminogen-mediated group A streptococcal adherence to and pericellular invasion of human pharyngeal cells. Microb. Pathog. 35, 293-303. doi: 10.1016/j.micpath.2003.08.004

Papasergi, S., Garibaldi, M., Tuscano, G., Signorino, G., Ricci, S., Peppoloni, S., et al. (2010). Plasminogen- and fibronectin-binding protein $B$ is involved in the adherence of Streptococcus pneumoniae to human epithelial cells. J. Biol. Chem. 285, 7517-7524. doi: 10.1074/jbc.M109.062075

Paterson, G. K., and Orihuela, C. J. (2010). Pneumococcal microbial surface components recognizing adhesive matrix molecules targeting of the extracellular matrix. Mol. Microbiol. 77, 1-5. doi: 10.1111/j.1365-2958.2010.07190.x

Plow, E. F., Freaney, D. E., Plescia, J., and Miles, L. A. (1986). The plasminogen system and cell surfaces: evidence for plasminogen and urokinase receptors on the same cell type. J. Cell Biol. 103, 2411-2420. doi: 10.1083/jcb.103. 6.2411

Pollanen, J., Stephens, R. W., and Vaheri, A. (1991). Directed plasminogen activation at the surface of normal and malignant cells. Adv. Cancer Res. 57, 273-328. doi: 10.1016/S0065-230X(08)61002-7 
Ponting, C. P., Marshall, J. M., and Cederholm-Williams, S. A. (1992). Plasminogen: a structural review. Blood Coagul. Fibrinolysis 3, 605-614. doi: 10.1097/00001721-199210000-00012

Ringdahl, U., and Sjöbring, U. (2000). Analysis of plasminogen-binding M proteins of Streptococcus pyogenes. Methods 21, 143-150. doi: 10.1006/meth.2000.0985

Sanderson-Smith, M. L., De Oliveira, D. M., Ranson, M., and McArthur, J. D. (2012). Bacterial plasminogen receptors: mediators of a multifaceted relationship. J. Biomed. Biotechnol. 2012, 272148. doi: 10.1155/2012/272148

Sanderson-Smith, M. L., Dinkla, K., Cole, J. N., Cork, A. J., Maamary, P. G., McArthur, J. D., et al. (2008). M protein-mediated plasminogen binding is essential for the virulence of an invasive Streptococcus pyogenes isolate. FASEB J. 22, 2715-2722. doi: 10.1096/fj.07-105643

Sanderson-Smith, M. L., Dowton, M., Ranson, M., and Walker, M. J. (2007). The plasminogen-binding group A streptococcal $M$ protein-related protein Prp binds plasminogen via arginine and histidine residues. J. Bacteriol. 189, 1435-1440. doi: 10.1128/JB.01218-06

Sanderson-Smith, M., Batzloff, M., Sriprakash, K. S., Dowton, M., Ranson, M., and Walker, M. J. (2006a). Divergence in the plasminogen-binding group a streptococcal M protein family: functional conservation of binding site and potential role for immune selection of variants. J. Biol. Chem. 281, 3217-3226. doi: 10.1074/jbc.M508758200

Sanderson-Smith, M. L., Walker, M. J., and Ranson, M. (2006b). The maintenance of high affinity plasminogen binding by group A streptococcal plasminogen-binding M-like protein is mediated by arginine and histidine residues within the al and a2 repeat domains. J. Biol. Chem. 281, 25965-25971. doi: 10.1074/jbc.M603846200

Seifert, K. N., McArthur, W. P., Bleiweis, A. S., and Brady, L. J. (2003). Characterization of group B streptococcal glyceraldehyde-3-phosphate dehydrogenase: surface localization, enzymatic activity, and protein-protein interactions. Can. J. Microbiol. 49, 350-356. doi: 10.1139/w03-042

Siemens, N., Patenge, N., Otto, J., Fiedler, T., and Kreikemeyer, B. (2011). Streptococcus pyogenes M49 plasminogen/plasmin binding facilitates keratinocyte invasion via integrin-integrin-linked kinase (ILK) pathways and protects from macrophage killing. J. Biol. Chem. 286, 21612-21622. doi: 10.1074/ jbc.M110.202671

Staats, J. J., Feder, I., Okwumabua, O., and Chengappa, M. (1997). Streptococcus suis: past and present. Vet. Res. Commun. 21, 831-407. doi: 10.1023/A:10058703 17757

Sun, H., Ringdahl, U., Homeister, J. W., Fay, W. P., Engleberg, N. C., Yang, A. Y., et al. (2004). Plasminogen is a critical host pathogenicity factor for group A streptococcal infection. Science 305, 1283-1286. doi: 10.1126/science. 1101245

Tang, J., Wang, C., Feng, Y., Yang, W., Song, H., Chen, Z., et al. (2006). Streptococcal toxic shock syndrome caused by Streptococcus suis serotype 2. PLoS Med. 3:e151. doi: 10.1371/journal.pmed.0030151

Teles, C., Smith, A., and Lang, S. (2012). Antibiotic modulation of the plasminogen binding ability of viridans group streptococci. Antimicrobial Agents Chemother. 56, 458-463. doi: 10.1128/AAC.00452-11
Terao, Y., Yamaguchi, M., Hamada, S., and Kawabata, S. (2006). Multifunctional glyceraldehyde-3-phosphate dehydrogenase of Streptococcus pyogenes is essential for evasion from neutrophils. J. Biol. Chem. 281, 14215-14223. doi: 10.1074/jbc. M513408200

Valenti-Weigand, P., Benkel, P., Rohde, M., and Chhatwal, G. S. (1996). Entry and intracellular survival of group B streptococci in J774 macrophages. Infect. Immun. 64, 2467-2473.

van der Linden, M., Al-Lahham, A., Nicklas, W., and Reinert, R. R. (2009). Molecular characterization of pneumococcal isolates from pets and laboratory animals. PLoS ONE 4:e8286. doi: 10.1371/journal.pone.0008286

Voss, S., Gámez, G., and Hammerschmidt, S. (2012). Impact of pneumococcal microbial surface components recognizing adhesive matrix molecules on colonization. Mol. Oral. Microbiol. 27, 246-256. doi: 10.1111/j.20411014.2012.00654.x

Walker, M. J., McArthur, J. D., McKay, F., and Ranson, M. (2005). Is plasminogen deployed as a Streptococcus pyogenes virulence factor. Trends Microbiol. 13, 308-313. doi: 10.1016/j.tim.2005.05.006

Winram, S. B., and Lottenberg, R. (1996). The plasmin-binding protein $\mathrm{Plr}$ of group A streptococci is identified as glyceraldehyde-3-phosphate dehydrogenase. Microbiology 142(Pt 8), 2311-2320. doi: 10.1099/13500872142-8-2311

Wistedt, A. C., Ringdahl, U., Muller-Esterl, W., and Sjobring, U. (1995). Identification of a plasminogen-binding motif in PAM, a bacterial surface protein. Mol. Microbiol. 18, 569-578. doi: 10.1111/j.1365-2958.1995. mmi_18030569.x

Yamaguchi, M., Terao, Y., Mori, Y., Hamada, S., and Kawabata, S. (2008). PfbA, a novel plasmin- and fibronectin-binding protein of Streptococcus pneumoniae, contributes to fibronectin-dependent adhesion and antiphagocytosis. J. Biol. Chem. 283, 36272-36279. doi: 10.1074/jbc.M807087200

Conflict of Interest Statement: The authors declare that the research was conducted in the absence of any commercial or financial relationships that could be construed as a potential conflict of interest.

Received: 12 August 2013; accepted: 06 November 2013; published online: 22 November 2013.

Citation: Fulde M, Steinert $M$ and Bergmann $S$ (2013) Interaction of streptococcal plasminogen binding proteins with the host fibrinolytic system. Front. Cell. Infect. Microbiol. 3:85. doi: 10.3389/fcimb.2013.00085

This article was submitted to the journal Frontiers in Cellular and Infection Microbiology.

Copyright (c) 2013 Fulde, Steinert and Bergmann. This is an open-access article distributed under the terms of the Creative Commons Attribution License (CC BY). The use, distribution or reproduction in other forums is permitted, provided the original author(s) or licensor are credited and that the original publication in this journal is cited, in accordance with accepted academic practice. No use, distribution or reproduction is permitted which does not comply with these terms. 